\title{
Effects of tobacco use during pregnancy on infant and child health
}

\author{
Birce Yüce ${ }^{1}$ (D), Funda İfakat Tengiz² \\ ${ }^{1}$ Izmir Katip Çelebi University Faculty of Medicine, Izmir, Turkey \\ ${ }^{2}$ Department of Medical Education, Izmir Katip Çelebi University Faculty of Medicine, Izmir, Turkey
}

\begin{abstract}
This review discusses the tobacco-using habits, especially cigarette smoking, of parents while focusing on women, before, during, and after pregnancy and the effects on the mother, infant, child, and prenatal fetus as well as the diseases that may occur. Data from many studies and surveys have shown that tobacco use causes various complications. Exposure of the in-utero fetus to tobacco smoke either directly or passively prevents its healthy and sufficient development. These effects persist after birth ranging among hypertension to obesity, insufficient lung development, neurodevelopment, behavioral problems, and many other fields. Without a doubt, this situation also causes similar problems in the mother as it does in the child.

Keywords: Baby health, fetal development, maternal health, pregnancy, tobacco use.
\end{abstract}

Tobacco use is a significant risk factor with harmful effects on the individual's health and life. Tobacco is a public health problem that can be considered the greatest preventable cause of death. ${ }^{[1]}$ Cigarettes, a tobacco product, is a top cause of death worldwide and approximately five million people die annually due to smoking. It is estimated that in the coming years, many people will lose their lives due to smoking if the number of people smoking cigarettes continues to increase. Smoking is a worldwide problem in many developed and developing countries. As in the entire society, in women, smoking which starts in adolescence and becomes a habit, may become a physiological and psychological addiction in later years. ${ }^{[2]}$ Increased cigarette use in the female population also causes increased risk during pregnancy caused by smoking. Because of the harm it causes the fetus, tobacco use in pregnant women is an even more significant health problem. Smoking during pregnancy or breathing passive tobacco smoke (passive smoking) negatively affects fertility, fetal development, every stage of pregnancy, and birth and also leads to negative outcomes including low birth weight, premature birth, stillbirth, and risky birth. Passive smoking originating from the parent, which leads to as many negative effects as active smoking on the infant or child's health, is a very common issue worldwide. Nicotine and carbon monoxide, the key ingredients of cigarettes, are harmful to the fetus's health. The fetus is fed through the placenta and umbilical cord. Since pregnant smoking women are unable to transport the oxygen needed by the fetus, the baby is not sufficiently fed and is unable to develop. ${ }^{[2]}$ Studies have shown that passive smoking during pregnancy also negatively impacts birth weight. ${ }^{[3]}$ Preventing exposure to tobacco smoke during pregnancy is still an important global subject and requires more research. Both pregnant women and close family should be educated about the harmful effects of active and passive smoking. Only non-smoking environments can prevent the risk of exposure to tobacco smoke. ${ }^{[4]}$ Quitting smoking in the first trimester (the period until twelve weeks of

Received: October 25, 2019 Accepted: February 28, 2020 Published online: August 25, 2020

Correspondence: Birce Yüce. İzmir Katip Çelebi Üniversitesi Tıp Fakültesi, 35620 Çiğli, İzmir, Türkiye. Tel: +90 541 - 7705787 e-mail: birceeyucee@gmail.com 
pregnancy) causes less harm to the in-utero fetus compared to other periods. The less the mother smokes, the less the fetus is affected. ${ }^{[2]}$ Due to all of the reasons mentioned above, tobacco use before, during and even after pregnancy is definitely not recommended due to the serious and wide range of illnesses it causes both mother and baby. It is very important to raise awareness on this issue. This review aims to discuss which smoking-related illnesses occur in which periods, which reasons they occur, or the likelihood they will occur. The main purpose is to raise awareness of this serious public health problem and to encourage people to be more cautious about potential risks.

\section{ILLNESSES THAT ARE THOUGHT TO BE CAUSED BY THE USE OF TOBACCO IN PREGNANCY}

Maternal smoking during pregnancy or exposure to tobacco smoke in the environment has been shown to be associated not only with fertility and fetal development, but also changes in postnatal growth and development. ${ }^{[3,5]}$ Maternal smoking during pregnancy increases the risk of significant outcomes in the long-term and is also well known to be associated with many fetal and developmental complications. In direct proportion to the increased number of cigarettes smoked during pregnancy, each stage and birth is affected and causes negative outcomes including low birth weight, preterm birth, sudden infant death syndrome, stillbirth, risky birth, fetal growth restriction, neurodevelopmental and behavioral problems, obesity, and hypertension. According to the 2008 data of the Turkey Demographic and Health Surveys, evaluation of the smoking-fertility status found that one in 10 pregnant women and $17 \%$ of breastfeeding women smoke. ${ }^{[3]}$ Results of the research showed that prenatal smoking (fetal life from the 20. week of pregnancy until birth) increases the risk of complications, affects the immune system of the fetus, and facilitates infection. It causes certain congenital anomalies (observance of physiological and morphological birth defects) and placental development disorder. ${ }^{[3]}$ Exposure to tobacco smoke in the environment without the person themselves smoking is called passive smoking. ${ }^{[6]}$

Pregnant women being exposed to tobacco smoke in their environment is a very dangerous situation and it is thought that regardless of whether or not the mother smokes herself, she is affected by the smoke of others, and inhalation of this smoke passes to the fetus through the placenta, preventing sufficient growth and development of the baby. ${ }^{[3,7]}$ The effects of smoking on the placenta include early membrane rupture, excessive vaginal bleeding, placenta previa and/or placenta abruption..$^{[2]}$ Studies have shown that smoking affects the fetal immune system, facilitates infections, increases congenital anomalies, and causes placental developmental disorders. ${ }^{[3]}$ Nicotine and carbon monoxide ingredients of tobacco smoke is thought to pass the placental barrier, harming both the mother and the fetus. ${ }^{[5]}$ In fact, other substances which may be found in nicotine and tobacco smoke may pass through the placenta as carbon monoxide (CO), polycyclic aromatic hydrocarbons, and tobaccospecific nitrosamines, entering fetal circulation and affecting the supply of oxygen. ${ }^{[8]}$

Expecting mothers who may be defined as passive smokers may encounter risks seen in direct smokers, including birth of a baby with low birth weight, congenital anomalies, or frequent illness, while mothers who are exposed to tobacco smoke in the environment may give birth to babies who later develop learning difficulties.

Smoking cigarettes, increased number of cigarettes smoked daily, increased smoking time, and being in the presence of other smokers increases the likelihood of developmental retardation of the fetus or newborn. ${ }^{[3]}$ In addition, smoking during pregnancy has been associated with long-term problems in cognitive function, general intelligence, academic success, psychiatric disorders, alcohol-substance abuse, affective disorder, criminal activity in adulthood, type 2 diabetes and obesity, childhood cancers, and chest diseases. ${ }^{[6,8]}$ In-utero exposure to tobacco smoke has a significant effect on the developing lungs, causing long-term/permanent structural changes, changes in pulmonary function, and increased risk of pulmonary disease and asthma. ${ }^{[9]}$ After birth, the baby is at increased risk of pneumonia and bronchitis. ${ }^{[2]}$ At the same time, it is also a preventable cause of premature birth, another important indicator of childhood respiratory function. ${ }^{[9]}$ The primary effects of maternal smoking on respiratory function and health include decreased forced expiratory 
flow, reduced availability of passive breathing, increased hospital length of stay due to respiratory infections, and increased prevalence of childhood diseases and asthma. Since nicotine is a top factor that affects lung development, it is possible that it may be dangerous for fetal lung development. In-utero exposure to smoke/nicotine may prevent the fetal lung from developing to its maximum capacity and may cause early lung deterioration and chronic obstructive pulmonary disease (COPD). ${ }^{[9]}$ Maternal smoking during pregnancy has been associated with risk of wheezing, asthma, airway hypersensitivity, impaired respiratory function, and bronchitis. ${ }^{[8]}$ A recent systematic review and meta-analysis reported that in-utero exposure was associated with increased risk of asthma and wheezing in children and adolescents up to 18 years of age, and was the strongest factor associated with incidence of childhood asthma. ${ }^{[8]}$ Different studies have indicated that intrauterine exposure to tobacco smoke decreases lung function, suggesting effects on small airway development with decreased tidal and forced expiratory flow rates. ${ }^{[8]}$

The carbon monoxide found in tobacco smoke has a great affinity for hemoglobin and, accordingly, increases the levels of carboxyhemoglobin in the umbilical arteries, prevents oxygen delivery to the cells, and causes fetal hypoxia. Moreover, resistance indices of uterine and umbilical arteries have been shown to increase in proportion to dosage of tobacco use. Low birth weight may be the result of an increase in resistance indices, resulting in decreased amount of blood and oxygen carried to the fetus. The presence of high $\mathrm{CO}$ level causes anemia in both the mother and fetus. Increased hematocrit level may cause increased blood viscosity in the mother, resulting in abnormal placental flow, which also leads to decrease in oxygen. ${ }^{[10]}$ Increased apoptosis is thought to result from mitochondrial dysfunction. ${ }^{[8]}$

Fetal growth restriction due to tobacco use during pregnancy may also be a result of epigenetic mechanisms. Indeed, exposure to tobacco smoke in the uterus has been associated with changes in deoxyribonucleic acid (DNA) methylation of genes associated with growth restriction. ${ }^{[8]}$ Maternal smoking during pregnancy has been found to affect neonatal DNA methylation in genes involved in fundamental developmental processes. ${ }^{[1]}$ In cord blood, methylation in seven gene regions is associated with maternal smoking, and a dose-related response is observed in relation to smoking time and intensity. ${ }^{[1]}$ Maternal drinking can regulate fetal brain development and function. In babies exposed to prenatal smoking, both decrease in brain size and changes in brain function may be observed compared to normal expected babies. ${ }^{[8]}$ Underlying mechanisms of these effects may include nicotine-modulating axonal pathway, synapse formation in neurons and $\mathrm{COs}$, and epigenetic changes in the brain derivative (such as regulation by DNA methylation) that inhibit fetal brain development (neurotrophic factor brain-derived neurotrophic factor (BDNF)-gene, which is required for normal brain development). ${ }^{[8]}$ There is an undeniable relationship between maternal smoking during pregnancy and attention deficit/hyperactivity disorder (ADHD). ${ }^{[12]}$

Maternal smoking has been shown to significantly decrease fetal serum bilirubin levels and infants whose mothers smoked cigarettes during pregnancy were at lower risk of neonatal jaundice compared to those with non-smoking mothers. ${ }^{[4]}$ More recently, other authors have indicated prevalence of dwarfism in children with intrauterine exposure to tobacco smoke..$^{[5]}$ Smoking is also among possible causes of anomalies such as cleft lip or cleft palate. ${ }^{[2]}$

One recent study showed that maternal smoking during pregnancy may increase the risk of the infant being born overweight. ${ }^{[8]}$ Children whose mothers smoked during pregnancy have exhibited rapid increase in body weight and they tend to be overweight in infancy and childhood. ${ }^{[13]}$ It was shown that children of mothers who smoked during their pregnancy had an increased risk of obesity at an average age of nine compared to children of mothers who did not smoke. Similarly, another meta-analysis reported that children whose mothers smoked during pregnancy had a $50 \%$ increased risk of becoming overweight later on compared to children whose mothers did not smoke during pregnancy. ${ }^{[8]}$ Studies have shown that the impact of maternal smoking during pregnancy on childhood growth is evident in gender differences. Smoking by pregnant mothers increases childhood weight gain, especially in boys, and as males grow older, they are more likely than girls to be affected by maternal 
smoking during pregnancy. ${ }^{[13]}$ However, there is also a possible relationship between paternal smoking and obesity risk in children. ${ }^{[8]}$

In conclusion, smoking and passive smoking during pregnancy continue to be a current public health issue due to the many severe and preventable complications as mentioned above.

\section{Declaration of conflicting interests}

The authors declared no conflicts of interest with respect to the authorship and/or publication of this article.

\section{Funding}

The authors received no financial support for the research and/or authorship of this article.

\section{REFERENCES}

1. Cheng $\mathrm{H}$, Furnham A. The Big-Five Personality Traits, Maternal Smoking during Pregnancy, and Educational Qualifications as Predictors of Tobacco Use in a Nationally Representative Sample. PLoS One 2016;11:e0145552.

2. Kublay G. Terzioğlu F, Karatay G. Gebelik ve Sigara. T.C. Sağllk Bakanlığı Temel Sağlık Hizmetleri Genel Müdürlüğü Beslenme ve Fiziksel Aktiviteler Daire Başkanlığ1 2008. https://havanikoru.saglik.gov.tr/ dosya/dokumanlar/sagligimiza_etkileri/Gebelik_ve_ Sigara.pdf [Accessed data: May 25, 2019]

3. Durualp E, Bektaş G, Ergin D, Karaca E, Topçu E. Annelerin sigara kullanımı ile yenidoğanın doğum kilosu, boyu ve baş çevresi arasındaki ilişkinin incelenmesi. Ankara Üniversitesi Tıp Fakültesi Mecmuasi 2011;64:119-26.

4. Huang $\mathrm{SH}$, Weng KP, Huang SM, Liou HH, Wang CC, Ou SF, et al. The effects of maternal smoking exposure during pregnancy on postnatal outcomes: A cross sectional study. J Chin Med Assoc 2017;80:796-802.

5. de Brito ML, Nunes M, Bernardi JR, Bosa VL, Goldani MZ, da Silva $\mathrm{CH}$. Somatic growth in the first six months of life of infants exposed to maternal smoking in pregnancy. BMC Pediatr 2017;17:67.

6. Tarhan P, Yllmaz T. Gebelikte Sigara Kullanımı ve Etkileyen Faktörler. HSP 2016;3:140-7.

7. Andriani $\mathrm{H}$, Kuo HW. Adverse effects of parental smoking during pregnancy in urban and rural areas. BMC Pregnancy Childbirth 2014;14:414.

8. Banderali G, Martelli A, Landi M, Moretti F, Betti F, Radaelli G, et al. Short and long term health effects of parental tobacco smoking during pregnancy and lactation: a descriptive review. $J$ Transl Med 2015;13:327.

9. McEvoy CT, Spindel ER. Pulmonary Effects of Maternal Smoking on the Fetus and Child: Effects on Lung Development, Respiratory Morbidities, and Life Long Lung Health. Paediatr Respir Rev 2017:21:27-33.

10. Wojtyła C, Głuszek Ł, Biliński P, Paprzycki P, Warzocha K. Smoking during pregnancy-hematological observations in pregnant women and their newborns after delivery. Ann Agric Environ Med 2012;19:836-41.

11. Richmond RC, Simpkin AJ, Woodward G, Gaunt TR, Lyttleton $\mathrm{O}$, McArdle $\mathrm{WL}$, et al. Prenatal exposure to maternal smoking and offspring DNA methylation across the lifecourse: findings from the Avon Longitudinal Study of Parents and Children (ALSPAC). Hum Mol Genet 2015;24:2201-17.

12. Gustavson K, Ystrom E, Stoltenberg C, Susser E, Surén $\mathrm{P}$, Magnus $\mathrm{P}$, et al. Smoking in Pregnancy and Child ADHD. Pediatrics 2017;139. pii: e20162509.

13. Suzuki K, Kondo N, Sato M, Tanaka T, Ando D, Yamagata Z. Maternal smoking during pregnancy and childhood growth trajectory: a random effects regression analysis. J Epidemiol 2012;22:175-8. 